XX Міжнародний симпозіум «Методи дискретних особливостей в задачах математичної фізики/Discrete Singularities Methods in Mathematical Physics», МДОЗМФ/DSMМРh-2021

УДК 532.528

MSC 76T10

\title{
Modeling of a ventilated cavity behind a streamlined body
}

\author{
G.O. Voropaiev, V.I. Korobov, N.F. Dimitrieva \\ Institute of Hydromechanics of the NAS of Ukraine, Kyiv, Ukraine \\ E-mail: Dimitrieva@nas.gov.ua
}

\begin{abstract}
The results of physical and numerical modeling of a ventilated air cavity behind a streamlined body are presented. The results of laboratory experiments to determine the amount of gas flowing from the ventilated cavity are presented. It is formed behind the cavitator depending on a number of geometric and dynamic parameters. Numerical simulation of non-stationary 3D two-phase flow was performed on the basis of open source software OpenFOAM. The influence of gas blowing parameters on the formation of an air cavity, size, shape and stability has been investigated. Good qualitative agreement with experimental data was obtained. It is shown that the thickness of the ventilated cavity is determined by the diameter of the cavitator regardless of the diameter of the blow hole, and the increase in velocity or gas flow rate has a positive effect on the length and stability of the formed cavity.
\end{abstract}

Key words: cavitation, two-phase flows, experiment, numerical simulation.

\section{Моделювання вентильованої каверни за обтічним тілом Г.О. Воропаєв, В.І. Коробов, Н.Ф. Димитрієва Інститут гідромеханіки НАН України, Київ, Україна E-mail: Dimitrieva@nas.gov.ua}

\begin{abstract}
Представлено результати фізичного і чисельного моделювання вентильованої повітряної каверни за обтічним тілом. Наведено результати лабораторних експериментів з визначення кількості газу, що витікає з вентильованої каверни, яка формується позаду кавітатора залежно від ряду геометричних і динамічних параметрів. На основі програмного забезпечення з відкритим кодом OpenFOAM проведено чисельне моделювання тривимірної нестаціонарної двофазної течії. Досліджено вплив параметрів продувки газу на формування повітряної порожнини, розмір, форму та стійкість. Отримано якісну узгодженість з експериментальними даними. Показано, що товщина вентильованої каверни визначається діаметром кавітатора не залежно від діаметра отвору видуву, а збільшення швидкості або витрати газу позитивно впливають на довжину та стійкість зформованої каверни.
\end{abstract}

Ключові слова: кавітація, двофазні течії, експеримент, чисельне моделювання.

\section{1. Ветуп}

Сьогодні проблема керування потоком залишається актуальною. Одним із способів зменшення опору є створення на обтічній поверхні порожнини, що заповнена парою або повітрям [1, 2], який в [3] називається суперкавітацією.

Явище природної гідродинамічної кавітації носить локальний характер і виникає лише там, де існують особливі умови для випаровування рідини. Таким станом може бути, наприклад, локальне зниження тиску в рідині зі збільшенням швидкості за обтічним тілом або в трубі зі змінним діаметром. Природню кавітацію важко

() Воропаєв Г.О., Коробов В.І., Димитрієва Н.Ф., 2021 
контролювати. Для створення і підтримки стабільної порожнини повітря часто примусово вдувається в паровмісну порожнину.

В даній роботі методами чисельного і фізичного моделювання вивчаються вентиляційні каверни за обтічним тілом із відносно низькою швидкістю течії. Науковий та практичний інтерес представляє аналіз геометричних та динамічних параметрів, що впливають на формування та розвиток повітряної порожнини, іiі розмір, форму та стійкість.

\section{2. Математичне моделювання}

За низьких швидкостей течії зміною фаз можна знехтувати у зв'язку з відсутністю умов природньої кавітації (випаровування) [4]. Для розв'язку задачі двофазного потоку (вода-повітря) використовується метод Volume of Fluid (VOF), який спирається на визначенні індикаторної функції для комірки розрахункової сітки [5]. Вводиться функція $\alpha\left(x_{j}, t\right)$, яка визначається для точок комірки і приймає значення 1 , якщо в точці є рідина. Якщо рідини немає, функція дорівнює нулю. Середнє значення $\alpha$ у всіх точках комірки дорівнює кількості рідини в комірці. Комірки зі значенням $\alpha$ від 0 до 1 повинні мати вільну поверхню, градієнти фазової частки зустрічаються лише в зоні зміни фаз. Таким чином, два середовища, що не змішуються, вважаються ефективною рідиною по всьому домену.

Перенос фазової частки визначається рівнянням:

$$
\frac{\partial \alpha}{\partial t}+\frac{\partial}{\partial x_{j}}\left(\alpha u_{j}\right)=0
$$

де $\alpha$ - фазова частка, $t$ - час, $u_{j}$ - компонента поля швидкості, $i, j=x, y, z$. У даному рівнянні зазначено, що $\alpha$ рухається разом з рідиною. Таким чином, метод VOF забезпечує простий та економічний спосіб відстеження вільних меж. В принципі, даний метод може бути використаний для відстеження поверхонь розриву фізичних властивостей матеріалу.

Рівняння неперервності та Нав’є Стокса записуються в наступному вигляді:

$$
\begin{gathered}
\frac{\partial u_{j}}{\partial x_{j}}=0 \\
\frac{\partial\left(\rho u_{i}\right)}{\partial t}+\frac{\partial}{\partial x_{j}}\left(\rho u_{i} u_{j}\right)=-\frac{\partial p}{\partial x_{i}}+\frac{\partial}{\partial x_{j}}\left(\mu \frac{\partial u_{i}}{\partial x_{j}}\right)+f_{\sigma i},
\end{gathered}
$$

де $p$ - тиск, $\mu$ - коефіцієнт динамічної в'язкості, густина суміші $\rho$ розраховується як середньозважене значення на основі фракційного розподілу рідини:

$$
\rho=\alpha \rho_{1}+(1-\alpha) \rho_{2},
$$

де $\rho_{1}$ - густина води, $\rho_{2}$ - густина повітря. Сила поверхневого натягу $f_{\sigma i}$ обчислюється наступним чином $[6,7]$ :

$$
f_{\sigma i}=\sigma \kappa \frac{\partial \alpha}{\partial x_{i}}, \quad \kappa=-\frac{\partial n_{i}}{\partial x_{i}}=-\frac{\partial}{\partial x_{i}}\left(\frac{\partial \alpha / \partial x_{i}}{\left|\partial \alpha / \partial x_{i}\right|}\right),
$$

де $\sigma$ - константа поверхневого натягу, к - кривизна поверхні розділу фаз [7]. 
XX Міжнародний симпозіум «Методи дискретних особливостей в задачах математичної фізики/Discrete Singularities Methods in Mathematical Physics», МДОЗМФ/DSMМPh-2021

\section{3. Чисельне моделювання}

Чисельне моделювання рівнянь (1-4) здійснюється в рамках відкритого програмного забезпечення OpenFOAM методом скінченних об'ємів [8]. Для розв'язку задачі двофазного потоку було застосовано чисельну модель interFoam для нестаціонарних ізотермічних двофазних течій, основною перевагою якої є можливість отримати прийнятні результати навіть із грубою сіткою [6].

Розрахункова область являє собою паралелепіпед розмірами $0,3 \times 0,3 \times 0,11$ м, на відстані відстані 0,015 м від початкового перерізу розташовано напівсферичне тіло (кавітатор) діаметром 0,005 м. В даній роботі запропоновано використання методики snappyHexMesh будування розрахункової сітки $[9,10]$. На першому етапі було побудовано фонову гексаедральну структуровану сітку з використанням утілити blockMesh. Далі сітку було наближено до геометричної поверхні за допомогою ітераційного покращення фонової сітки та підгонки отриманих розщеплених гексаелементів. На наступному кроці проводиться додаткове розбиття елементів в заданих особливих областях, в результаті чого отримуємо «ступінчасту» сітку. Налаштування рівня покращення вихідної сітки дуже гнучке. Таким чином, побудовано розрахункову сітку, що врахувує мілкомасштабні елементи течії в зоні фазового переходу та поблизу обтічного тіла. Тривимірна сітка складається з близько $2,5 \cdot 10^{6}$ комірок, 98\% з яких є гексаелементами. Мінімальна комірка має об'єм порядку $10^{-5} \mathrm{Mм}^{3}$.

На вході задавалася постійна швидкість рідини $U_{0}=1 \mathrm{~m} / \mathrm{c}$, на стінці кавітатора - умова прилипання. В момент часу $\mathrm{t}=0$ рідка фаза $\alpha=1$ задається по всій області, крім отвору для вдуву повітря. Параметри вдуву задаються за допомогою утиліти setFields. На задній стінці кавітатора визначалася зона зі спеціальними граничними умовами, в якій задавалася відсутність рідкої фази $\alpha=0$ і постійна швидкість $U_{c}$. Об'ємна витрата газу через отвір $\mathrm{Q}=U_{c} S$ змінювалася шляхом зміни швидкості вдуву $U_{c}$ і площі отвору $S$. Використовуючи утиліту setFields, не було потреби перебудовувати сітку при зміні параметрів отвору.

\section{4. Фізичне моделювання}

Експерименти проводилися в гідродинамічної трубі (ГДТ) з закритою робочою частиною яка має квадратний поперечний переріз розміром $0,4 \times 0,4$ м і довжину 1,8 м. Кавітатор встановлювався на порожнистій державці посередині робочої ділянки ГДТ. Всередині пілона проходить магістраль для підведення газу, піддув каверни здійснювався повітрям від компресора.

Величина витрати визначалася за перепадом тиску в трубці Вентурі, яка включена в магістраль наддуву, за допомогою диференціального датчика тиску. Швидкість потоку $U_{0}$ визначалася за величиною швидкісного напору в робочій ділянці ГДТ, який реєструвався за допомогою приймача ПВД і диференціального датчика тиску. Інформація, яка отримувалася з усіх датчиків тиску, реєструвалася на цифровому осцилографі Tektronix TDS 2014 В з наступною обробкою на ПЕОМ. Геометричні параметри каверни реєструвалися за допомогою цифрової фотокамери одномоментно з реєстрацією параметрів тиску.

Тестові експерименти показали, що каверна утворюється на малих швидкостях при деякому пороговому значенні витрати газу, менше якого вона має нестійку форму і об'єм і являє собою бульбашкову структуру. 


\section{5. Результати і обговорення}

Чисельні і фізичні експерименти показали, що в сліді за тілом утворюється стійка газоподібна каверна (рис. 1). Товщина вентильованої каверни визначається діаметром кавітатора, що узгоджується з даними $[1,3]$. Стійкість форми каверни залежить від швидкості обтікання і витрати повітря. За низьких значень витрати газоподібна каверна має нестійку форму і об'єм і має нестаціонарну нестійку бульбашкову структуру.

Чисельні результати (рис. 1, б) показали симетричну форму газоподібної каверни, що наближена до еліпсоідальної. Перш за все, це пов'язано з тим, що в розрахунках силою тяжіння було знехтувано з метою вивчення процесу формування каверни залежно від швидкості та геометрії отвору видуву газу без впливу зовнішніх факторів. А експериментальні дані показали викривлення каверни у вертикальному напрямку в наслідок впливу гравітації і спливання бульбашок в сліді (рис. 1, а).

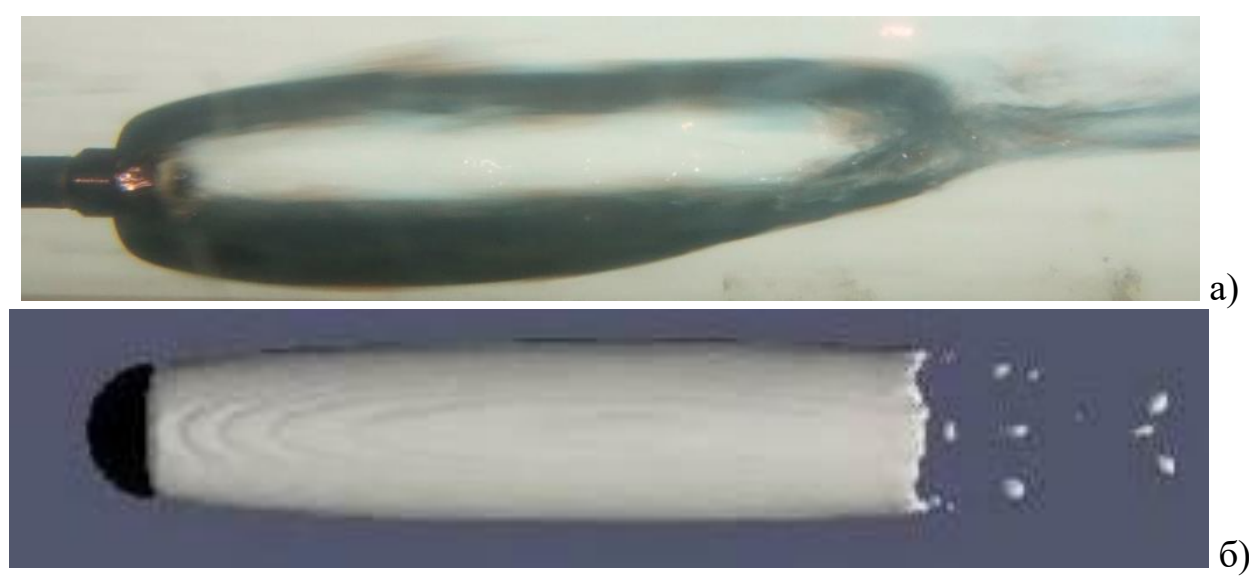

Рис. 1 Миттєві картини зформованої вентильованої каверни: експериментальні дані (а), чисельні розрахунки (б)

Найбільш суттєві відмінності результатів чисельних розрахунків від даних експерименту спостерігаються в задній частині повітряної каверни. Дані експериментів показали поступове зменшення діаметру вздовж каверни. В результаті обчислень газова каверна в кормі втрачає суцільність у формі корони, а бульбашки періодично вириваються з гострих країв поверхні розділу фаз. Варто відзначити, відокремлені бульбашки відносяться далі в потік рідини у вигляді вихрового сліду, що якісно збігається з експериментальними картинами фотореєстрації (рис. 2).
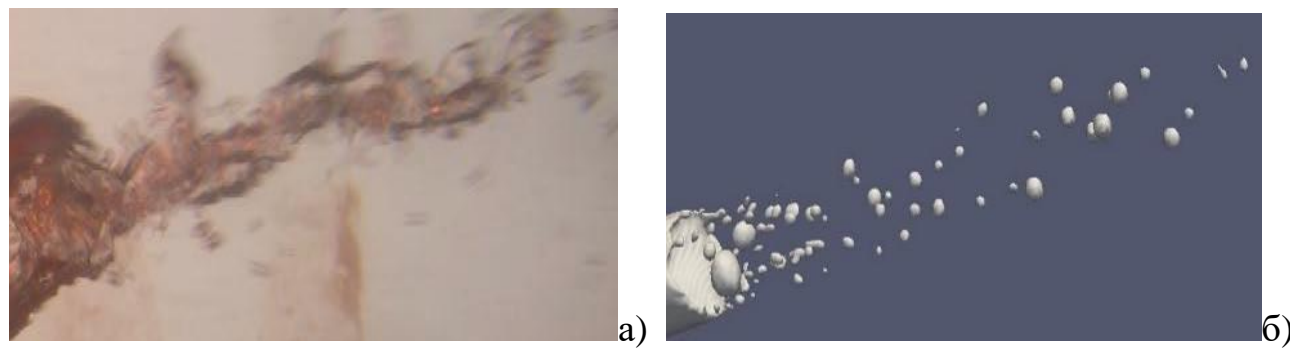

Рис. 2 Бульбашковий слід за каверною: експеримент (а), розрахунки (б) 
XX Міжнародний симпозіум «Методи дискретних особливостей в задачах математичної фізики/Discrete Singularities Methods in Mathematical Physics»,

\section{МДОЗМФ/DSMMPh-2021}

В рамках даної роботи досліджувався вплив різних параметрів на структуру двофазної течії. Результати чисельних розрахунків показали, що зменшення швидкості видуву впливає на довжину двофазної кормової частини каверни і її стійкість. При збільшенні витрати газу у двічі довжина суцільної і двофазної частин каверни зростає майже у півтора рази. При цьому максимальний діаметр каверни практично не змінився і дорівнює приблизно $1,35 d$.

За подібності форм каверни при зміні об'ємних витрат і величин швидкості осьового вдуву газу вихровий рух газу всередині каверни, яке визначається не тільки швидкістю вдуву, але і в'язкою напругою на межі каверни, істотно різний. Так при $\mathrm{Q}=4 \mathrm{~cm}^{3} / \mathrm{c}$ і $U_{c}=0.2 \mathrm{~m} / \mathrm{c}$ газ, що вдувається, за кавітатором, розподіляється по поверхні каверни, компенсуючи в'язкий винесення газу зовнішнім потоком [11], а всередині каверни утворюється замкнений стійкий вихровий потік газу до межі розділу фаз $L_{g} / d \approx 3$ (рис. 3 , крива 1 ). За межею розділу фаз утворюється нестійкий вихор зворотного закрутки, що можна вважати областю двофазного замикання газової каверни $L_{k} / d \approx 5$. Нижче за течією при $z / d>5$ формується двофазний слід (рис. 4, криві 4-6). При збереженні витрати, але збільшенні швидкості осьового вдуву газу $\left(U_{c}=1.0 \mathrm{~m} / \mathrm{c}\right)$ осьовий струмінь втрачає свою форму на довжині $l \approx 2 d$, приблизно на цю величину збільшуючи довжину стійкої частини каверни $L_{k} / d \approx 4$ (рис 3, крива 2), довжина двофазної області каверни і слід практично зберігаються. При збільшенні витрати і швидкості осьового вдуву газу в два рази область струменевої течії всередині каверни збільшується до $l \approx 4 d$. Однак сумарна довжина однофазної області каверни збільшується тільки до $L_{k} / d \approx 6$, значно скорочуючи область вихрової зворотної течії (рис. 3, крива 3). Довжина двофазної області каверни, що замикає каверну, і профіль швидкості в сліді практично не змінюється, але концентрація газової фази в сліді збільшена майже в два рази.

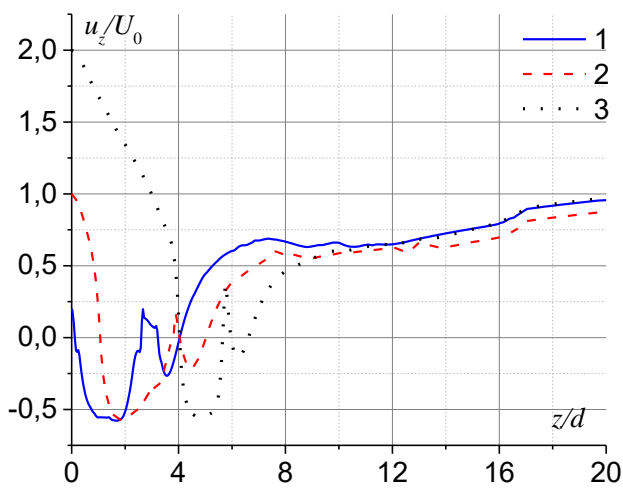

Рис 3: Розподіл поздовжньої компоненти швидкості вздовж вісі $z$ при $x, y=0$ :

$$
\begin{gathered}
1-U_{c}=0,2 \mathrm{M} / \mathrm{c}, S=20 \cdot 10^{-6} \mathrm{M}^{2}, \\
Q=4 \cdot 10^{-6} \mathrm{~m}^{3} / \mathrm{c} ; 2-U_{c}=1 \mathrm{M} / \mathrm{c}, \\
S=4 \cdot 10^{-6} \mathrm{M}^{2}, Q=4 \cdot 10^{-6} \mathrm{~m}^{3} / \mathrm{c} \\
3-U_{c}=2 \mathrm{M} / \mathrm{c}, S=4 \cdot 10^{-6} \mathrm{M}^{2}, \\
Q=8 \cdot 10^{-6} \mathrm{M}^{3} / \mathrm{c}
\end{gathered}
$$

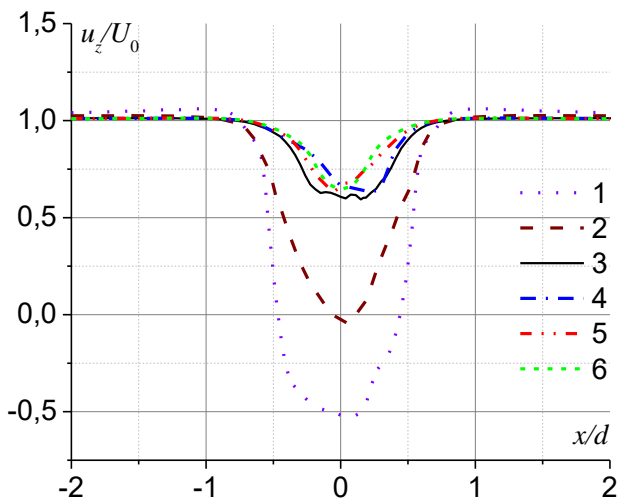

Рис 4: Розподіл поздовжньої компоненти швидкості в центральному перерізі впоперек основному потоку на різних відстанях від кавітатора: $1-z=2 d$, $2-z=4 d, 3-z=6 d, 4-z=8 d$, $5-z=10 d, 6-z=12 d$ $\left(U_{0}=1 \mathrm{M} / \mathrm{c}, U_{c}=1 \mathrm{M} / \mathrm{c}\right)$ : 


\section{6. Висновки}

Запропоновано методику фізичного і чисельного дослідження штучно вентильованої газоподібної каверни за обтічним тілом за низьких чисел Рейнольдса, коли відсутні умови утворення природньої парової каверни. Досліджено вплив геометричних та динамічних параметрів продувки газу на формування повітряної порожнини, розмір, форму та іï стійкість. Отримано якісну узгодженість 3 експериментальними даними. Показано, що максимальна товщина вентильованої каверни визначається діаметром обтічного тіла не залежно від діаметра отвору видуву, а збільшення витрати газу позитивно впливають на довжину та стійкість сформованої каверни.

\section{ЛІТЕРАТУРА}

1. Wang B., Wang J., Chen D. et al. Experimental Investigation on Underwater Drag Reduction Using Partial Cavitation. Chin. Phys. B. 2017. V. 26, № 5. P. 054701.

2. Amromin E., Mizine I. Partial Cavitation as Drag Reduction Technique and Problem of Active Flow Control. Marine Technology. 2003. V. 40, № 3. P. 181-188.

3. Supercavitation: Advances and Perspectives. Ed. I.Nesteruk. Springer-Verlag, Berlin and Heidelberg, 2012.

4. Димитрієва Н.Ф., Воропаєв Г.О., Фаль В.О. Методика розрахунку утворення парової каверни за обтічним тілом. Тези сьомої міжнародної науковопрактичної конференції «Комп'ютерна гідромеханіка» (Київ, 29-30 вересня 2020 р.). Київ : ІГМ НАНУ. 2020. с.27-28.

5. Hirt C.W., Nichols B.D. Volume of Fluid (VOF) Method for the Dynamics of Free Boundaries, J. Comp. Phys. 1981. V. 39, № 1. P. 201-225.

6. Deshpande S.S., Anumolu L., Trujillo M.F. Evaluating the performance of the twophase flow solver interFoam Computational science \& discovery. 2012. V. 5, № 1. 3. 014016.

7. Brackbill J.U., Kothe D.B., Zemach C. A continuum method for modeling surface tension J. Comp. Phys. 1992. V. 100, № 2. P. 335-354.

8. Damián S.M. Description and utilization of interFoam multiphase solver Comp.Fluid Dyn. 2012.

9. Читалов Д.И., Калашников С.Т. Разработка приложения для подготовки расчетных сеток посредством утилиты snappyHexMesh программной среды OpenFOАМ. Программные продукты и системы. 2018. Т. 31, № 4. С. 715-722.

10. Epikhin1 A., Evdokimov I., Kraposhin M., et al. Development of a Dynamic Library for Computational Aeroacoustics Applications Using the OpenFOAM Open Source Package Procedia Computer Science. 2015. V. 66. P. 150-157.

11. Воропаев Г.А. Вязкое вовлечение газа в вентилируемой каверне заданной формы. 2013. Прикладная гидромеханика Т. 15, № 1. С. 10-23. 
XX Міжнародний симпозіум «Методи дискретних особливостей в задачах математичної фізики/Discrete Singularities Methods in Mathematical Physics»,

\section{МДОЗМФ/DSMМPh-2021}

\section{Моделирование вентилируемой каверны за обтекаемым телом}

Г.А. Воропаев, В.И. Коробов, Н.Ф. Димитриева

Інститут гидромеханики НАН Украины, Киев, Украина

E-mail: Dimitrieva@nas.gov.ua

Представлены результаты физического и численного моделирования вентилируемой воздушной каверны за обтекаемым телом. Приведены результаты лабораторных экспериментов по определению количества газа, изтекаемого из вентилируемой каверны, которая формируется за кавитатором, в зависимости от ряда геометрических и динамических параметров. На основании программного обеспечения с открытым кодом OpenFOAM проведено численное моделирование трехмерного нестационарного двухфазного течения. Исследовано влияние параметров продувки газа на формирование воздушной полости, размер, форму и стойкость. Получено качественное когласование с экспериментальными данными. Показано, что толщина вентилируемой каверны определяется диаметром кавитатора независимо от диаметра отверстия выдува, а увеличение скорости или расхода газа позитивно влияют на длину и устойчивость сформированной каверны.

Ключові слова: кавітація, двофазні течії, експеримент, чисельне моделювання. 